\title{
Microstructural analysis of creep exposed IN617 alloy
}

\author{
R. Krishna, S.V. Hainsworth* H.V. Atkinson and A. Strang ${ }^{1}$
}

Nickel base alloys such as IN617 are one of the preferred choices for steam turbine components used by fossil fuelled power generation plants. IN617 is a solid-solutionstrengthened nickel-based superalloy containing $~ 23 \% \mathrm{Cr}, 12 \% \mathrm{Co}$, and $9 \%$ Mo with low content of precipitation-strengthening elements $\mathrm{Al}, \mathrm{Ti}$ and $\mathrm{Nb}$. In the 'as-received' (solution-annealed condition), the microstructure consists of primary carbides $\left(\mathrm{M}_{23} \mathrm{C}_{6}\right)$ and occasional TiN particles dispersed in a single-phase austenitic matrix. Owing to high temperature exposure and the creep deformation processes that occur in-service, evolution of the microstructure occurs. This results in secondary precipitation and precipitate coarsening, both on grain boundaries and intragranularly in areas of high dislocation density. The influence of creep deformation on the solution-treated IN617 alloy at an operating condition of $650^{\circ} \mathrm{C} / 574 \mathrm{Hrs}$, with emphasis on the morphology and distribution of carbide/nitride precipitation is discussed. The applied stress was at an intermediate level.

Keywords: IN617; Solid-solution strengthening; Hardness; Intergranular fracture; Precipitates; Microstructural stability; FEGSEM; TEM.

\section{Introduction}

The fundamental requirement to increase the efficiency of fossil fuelled power plants is to raise the working thermal efficiency. Higher thermal efficiencies can be achieved by raising the steam operating pressure and temperature. The current thermal efficiencies of power plants are around $45 \%$, typically operating at $30 \mathrm{MPa}$ steam pressure and $600^{\circ} \mathrm{C}$ steam temperature [1]. Recently, ultra-supercritical steam conditions up to $700^{\circ} \mathrm{C}$ and $37.5 \mathrm{MPa}$, have been under consideration to increase the thermal efficiencies to about $50 \%$ or more [2-5]. This has prompted the selection and identification of stronger high temperature materials, capable of operating under

\footnotetext{
${ }^{1}$ Department of Engineering, University of Leicester, University Road, Leicester, LE1 7RH, UK

*Corresponding author, svh2@le.ac.uk
} 
higher stresses at ever increasing temperatures. The required high temperature material properties for longer life are good creep-rupture strength, long term microstructural and metallurgical stability, good fatigue resistance, higher fracture toughness and excellent corrosion and oxidation resistance in aggressive operating environments [6]. Ni-based superalloys have been under investigation for steam turbine components to meet these stringent material targets from the early 1970s. Among the nickel-based superalloy family, IN617 was originally developed as a solidsolution-strengthened alloy and is now one of the preferred structural materials for future generation steam turbines and their components [7-11]. In the present work, microstructural changes in creep exposed IN617 alloy, relevant to a plant operating temperature of $650^{\circ} \mathrm{C}$, were evaluated.

IN617 is a nickel-based austenitic superalloy having a face-centered-cubic (FCC) crystal structure and primarily strengthened by solid-solution hardening. Additional hardening is provided by the fine intermetallic precipitates, embedded in the disordered austenitic matrix phase [12]. Alloying elements like $\mathrm{Cr}, \mathrm{Co}, \mathrm{Mo}, \mathrm{Al}, \mathrm{Ti}, \mathrm{Fe}$ etc are responsible for elevated temperature structural and mechanical performance. Solutes like $\mathrm{Cr}$, Co, Mo provide solid solution strengthening to the austenitic matrix and contribute to secondary hardening by localized carbide and nitride precipitation after ageing heat-treatment and during exposure at service temperatures. Solutes like $\mathrm{Al}, \mathrm{Ti}$ and $\mathrm{Nb}$ provide additional precipitation strengthening by coherent intermetallic precipitation [13-14].

The precipitation of carbides such as $\mathrm{M}_{23} \mathrm{C}_{6}(\mathrm{M}=\mathrm{Cr}$, Co, Mo), $\mathrm{MC}$, and $\mathrm{MN}(\mathrm{M}=\mathrm{Ti})$, within the grains and at grain boundaries, during service exposure, is a common phenomenon in Ni-based superalloys [15-16]. On exposure to high temperatures under mechanical stresses in aggressive environmental conditions with time the mechanical properties of the alloys degrade, owing to changes that occur in their microstructures. The degradation of properties can ultimately lead to failure of components in service [17].

This paper presents the effect of intermediate applied stress, time and temperature (574 Hrs and $650^{\circ} \mathrm{C}$ ) on IN617. These conditions are relevant to future power plant. Precipitate evolution and morphology have been studied with scanning and transmission electron microscopy. The evolution of mechanical properties has been investigated using hardness testing. Finally, the creep failure mechanism of the failed sample has been investigated by observation of the fracture surfaces and cross-sections through the fracture by scanning electron and optical microscopy respectively. 


\section{Material used and experimental procedures}

\subsection{Material chemical composition and heat-treatment}

The complete nominal chemical composition of 'as received' IN617 is given in Table 1. A standard creep rupture specimen was prepared from a solution-annealed forged rod of IN617. The ASTM grain size number and hardness of the 'as received' specimen were 5.0 and $186.6 \pm 5 \mathrm{H}_{\mathrm{V}} / 20$ respectively.

Table 1: Chemical composition of IN617 (in weight \%)
\begin{tabular}{|c|c|c|c|c|c|c|c|c|c|c|}
\hline Elements & $\mathrm{Ni}$ & $\mathrm{Cr}$ & $\mathrm{Mo}$ & $\mathrm{Co}$ & $\mathrm{Al}$ & $\mathrm{Ti}$ & $\mathrm{Fe}$ & $\mathrm{C}$ & $\mathrm{Si}$ & $\mathrm{W}$ \\
\hline $\mathrm{Wt} \%$ & $\mathrm{Bal}$. & 22.8 & 9.0 & 11.9 & 1.15 & 0.48 & 0.35 & 0.06 & 0.05 & 0.02 \\
\hline Elements & $\mathrm{Mn}$ & $\mathrm{Cu}$ & $\mathrm{Zr}$ & $\mathrm{P}$ & $\mathrm{V}$ & $\mathrm{N}$ & $\mathrm{Nb}$ & $\mathrm{S}$ & \multicolumn{2}{|c|}{$\mathrm{B}$} \\
\hline Wt \% & 0.02 & 0.013 & 0.005 & 0.005 & 0.005 & 0.004 & 0.003 & 0.001 & 0.0002 \\
\hline
\end{tabular}

The solution-annealed forged rods $\left(1100^{\circ} \mathrm{C} / 3 \mathrm{Hrs} / \mathrm{WQ}\right)$ were given a heat-treatment $\left(670^{\circ} \mathrm{C} / 10\right.$ Hrs/ AC) which usually precipitates primary carbides only on grain boundaries (Fig. 1). Creep-test specimens were then machined from the rods. The creep rupture test was conducted at $650^{\circ} \mathrm{C}$ under an applied intermediate stress in air by ALSTOM Power Ltd. Rugby, UK. The creep test was continued until fracture occurred.

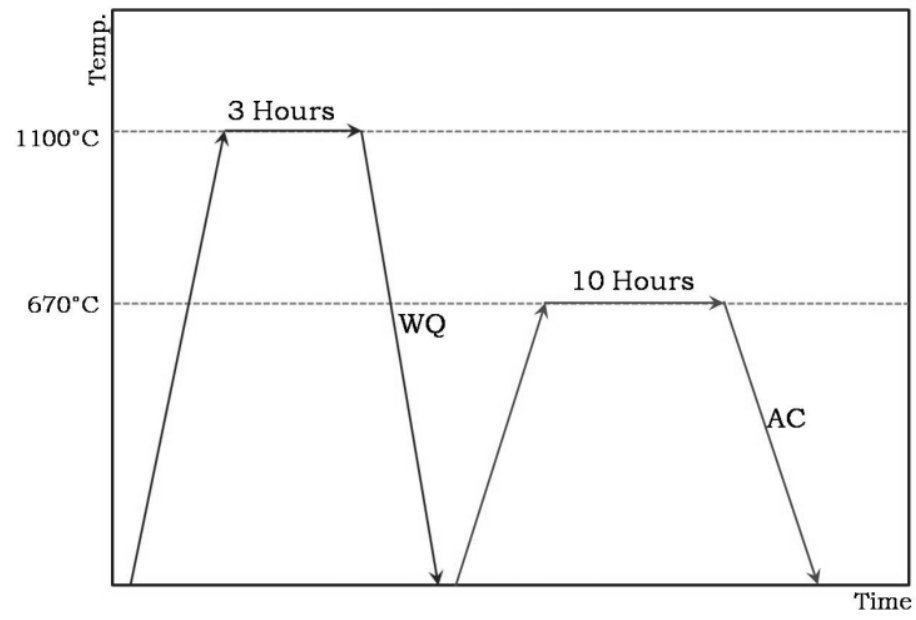

Figure 1. Heat-treatment cycle. 


\subsection{Hardness and microstructural observations}

Vickers hardness tests were conducted using a Vickers hardness testing machine, with a $20 \mathrm{kgf}$ load on ground and polished longitudinal cross-section of the creep fractured specimen. The failure mechanism of the creep exposed sample was evaluated by using environmental scanning electron microscopy (ESEM). The metallography was conducted on the specimen after etching in glyceregia, which is a mixture of hydrochloric acid, glycerol and nitric acid in a 3:2:1 ratio, using optical (OM) and scanning electron (FEGSEM) microscopy. The Heyn lineal intercept method was used to measure the average grain size on optical micrographs of 'as-received' and creep-exposed samples [18].

The area fractions of phases were determined on different fields of view, at magnifications of 5,000 to 10,000, on back-scattered electron (BSE) FEGSEM micrographs. These magnifications were chosen because they were high enough to resolve the phase morphology. The representative area fractions are the mean of individual area fractions of phases. The standard errors were in the range from $0.1 \%$ to $3.4 \%$.

Thin foils having thickness ranging from 0.10 to $0.12 \mathrm{~mm}$ and a diameter of $3 \mathrm{~mm}$ were prepared from the gauge length of the creep exposed specimen for transmission electron microscopy analysis. These foils were mechanically polished and subsequently subjected to twinjet electro polishing in a solution of methanol with $20 \mathrm{vol} \%$ perchloric acid at $-22^{\circ} \mathrm{C}$ under an applied potential of $14 \mathrm{~V}$.

\subsection{X-ray diffractometry (XRD) and peaks separation}

X-ray diffractometry (XRD) was performed using a Philips PW 1716 diffractometer with $\mathrm{CuK} \alpha_{1}$ radiation $(\lambda=1.54 \AA)$ in the angular range of $2^{\circ} \leq 2 \theta \leq 125^{\circ}, \Delta 2 \theta=0.0096^{\circ}, t=0.5 \mathrm{~s} / \mathrm{step}$, to characterize the phases present in the creep failed sample. Some potential precipitate peaks overlap with the austenitic $\gamma$-matrix peaks. PeakFit ${ }^{\circledR}[19,20]$ software was used to separate the peaks. 


\section{Results and discussion}

\subsection{Microstructural stability of creep exposed alloy}

Fig. 2 shows the optical microstructures of the 'as-received' (solution-annealed) and IN617 sample creep exposed at $650^{\circ} \mathrm{C}$ for $574 \mathrm{Hrs}$ at an intermediate stress. The 'as-received' sample shows an equiaxed austenitic grain structure (Fig. 2a). The grain orientation has previously been shown to be random [21]. Twins and twinning boundaries are observed in a number of grains. The grain size varied from a minimum $70 \mu \mathrm{m}$ to a maximum $440 \mu \mathrm{m}$ with an average size of $120 \mu \mathrm{m}$. The austenitic grain structure of the creep-exposed IN617 sample is shown in Fig. 2b. The grain size of the creep-exposed sample varied from a minimum of $46 \mu \mathrm{m}$ to a maximum of $544 \mu \mathrm{m}$ with an average size of approximately $158 \mu \mathrm{m}$.
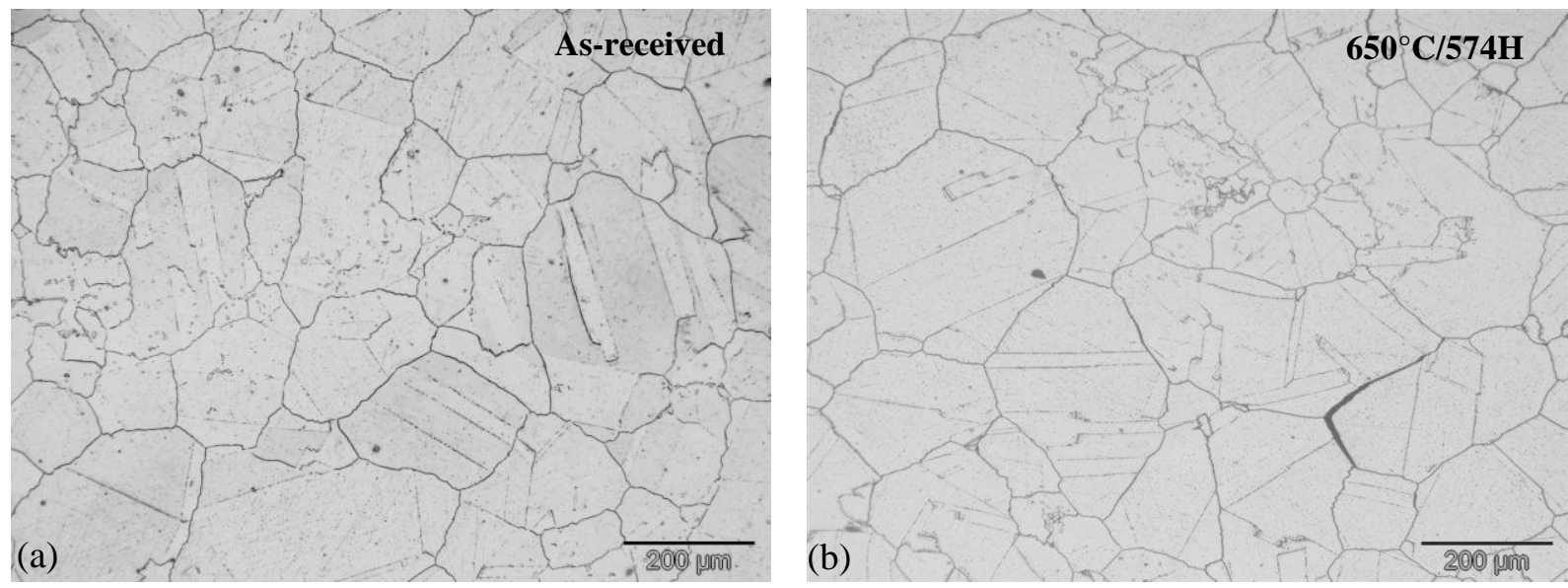

Figure 2 Optical micrographs of IN617 (a) 'as-received', (b) creep-exposed at $650^{\circ} \mathrm{C}$ for $574 \mathrm{Hrs}$ at intermediate stress, from the longitudinal gauge section, $2 \mathrm{~cm}$ behind the fracture surface.

Fig. 3 and Fig. 4 show montages of scanning electron microscope (SEM) images of asreceived and creep-exposed IN617 samples, respectively. Carbides are present in the matrix and at grain boundaries. The grain boundary precipitates are mostly rich in chromium, when analysed by energy dispersive X-ray microanalysis (EDS). The blocky particles $\mathrm{M}(\mathrm{C}, \mathrm{N})$, are mainly composed of titanium, when analysed by EDS, and are randomly distributed in the matrix and at twin boundaries. They will be referred to in the paper as $\mathrm{Ti}(\mathrm{C}, \mathrm{N})$. The XRD result (see later) shows the precipitates to be Cr-rich $\mathrm{M}_{23} \mathrm{C}_{6}$ carbides and Ti $(\mathrm{C}, \mathrm{N})$. The Cr-rich $\mathrm{M}_{23} \mathrm{C}_{6}$ carbides will be referred to as $\mathrm{Cr}_{23} \mathrm{C}_{6}$ in the paper. The 'as-received' SEM micrograph (Fig. 3) indicates that precipitates of 
size less than $2 \mu \mathrm{m}$ are situated in inter-granular regions and some larger particles within the grains. The morphology of the precipitates was found to vary considerably from irregular geometries to a more symmetrical cubic geometry. Cr-rich precipitates $\left(\mathrm{M}_{23} \mathrm{C}_{6}\right)$ varied in size from $1 \mu \mathrm{m}$ to $6 \mu \mathrm{m}$ and occupied an area fraction of $1.4 \%$. Ti-rich precipitates (TiC/TiN) were observed to range in size from $2 \mu \mathrm{m}$ to $10 \mu \mathrm{m}$, and the area fraction was $0.3 \%$.

Table 2: Precipitate evolution after creep exposure

\begin{tabular}{|c|c|c|c|c|c|}
\hline \multirow[b]{2}{*}{ Specimen ID } & \multirow[b]{2}{*}{ Precipitate Location } & \multicolumn{3}{|c|}{ Precipitates Morphology } & \multirow[b]{2}{*}{$\begin{array}{c}\text { Area } \\
\text { Fraction }(\%)\end{array}$} \\
\hline & & & $\begin{array}{l}\text { Size } \\
(\mu \mathrm{m})\end{array}$ & Shape & \\
\hline \multirow{2}{*}{ As-received } & \multirow{2}{*}{$\begin{array}{l}\text { Intra- and inter- } \\
\text { granularly }\end{array}$} & $\mathrm{Ti}(\mathrm{C}, \mathrm{N})$ & $2-10$ & \multirow{4}{*}{$\begin{array}{l}\text { Symmetrical to } \\
\text { totally } \\
\text { asymmetrical } \\
\text { geometry }\end{array}$} & 0.3 \\
\hline & & $\mathrm{Cr}_{23} \mathrm{C}_{6}$ & $1-6$ & & 1.4 \\
\hline \multirow{2}{*}{$\begin{array}{c}\text { Creep-exposed } \\
\left(650^{\circ} \mathrm{C} / 574 \mathrm{H} / \text { Intermediate }\right. \\
\text { stress })\end{array}$} & \multirow{2}{*}{$\begin{array}{l}\text { Extensive } \\
\text { precipitation of } \mathrm{Cr}- \\
\text { enriched particles on } \\
\text { grain boundaries and } \\
\text { twin boundaries }\end{array}$} & $\mathrm{Ti}(\mathrm{C}, \mathrm{N})$ & $3-5$ & & 0.8 \\
\hline & & $\mathrm{Cr}_{23} \mathrm{C}_{6}$ & $1-17$ & & 6.3 \\
\hline
\end{tabular}

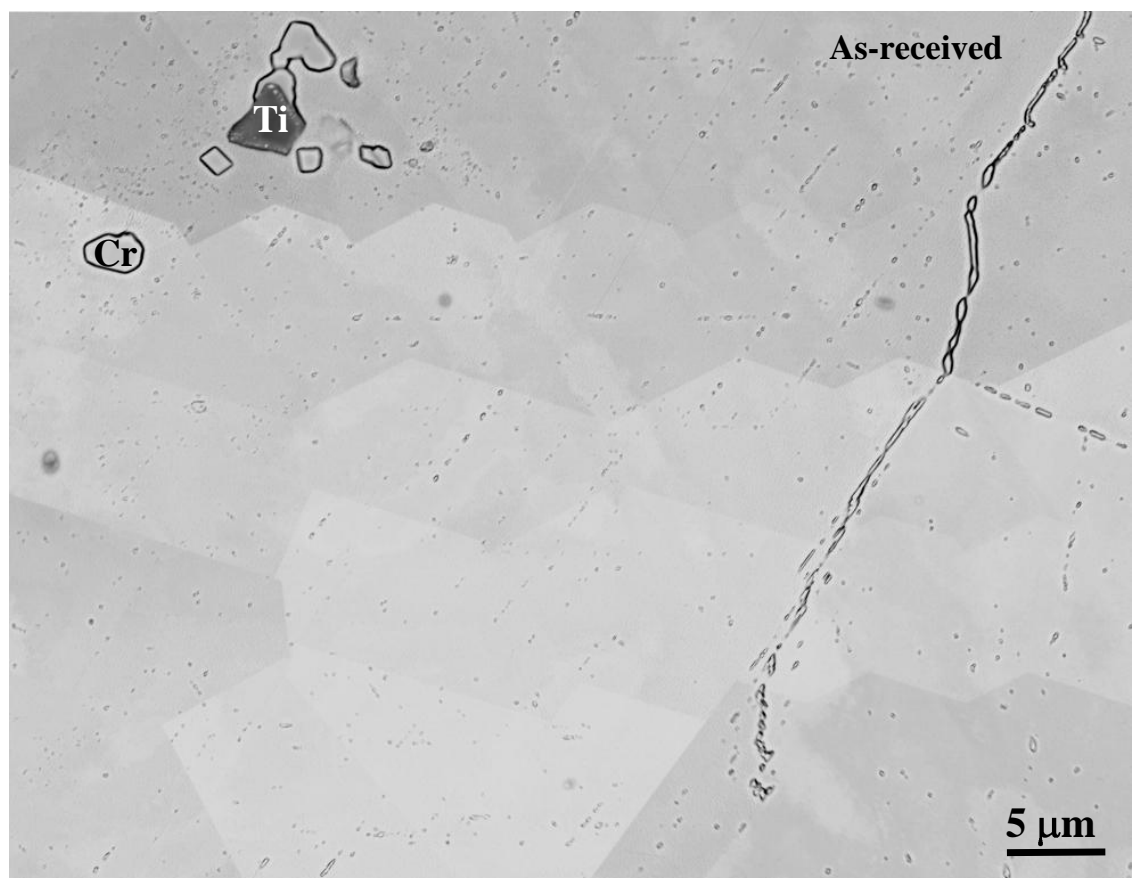

Figure 3 Scanning electron micrograph of 'as-received' IN617. Blocky shape (darker contrast) particle (' $\mathrm{Ti}$ ') is $\mathrm{Ti}(\mathrm{C}, \mathrm{N})$ and grey contrast particles (' $\mathrm{Cr}$ ') are $\mathrm{Cr}_{23} \mathrm{C}_{6}$, distributed intra-granularly. $\mathrm{Cr}_{23} \mathrm{C}_{6}$ are also present on the grain boundary. 


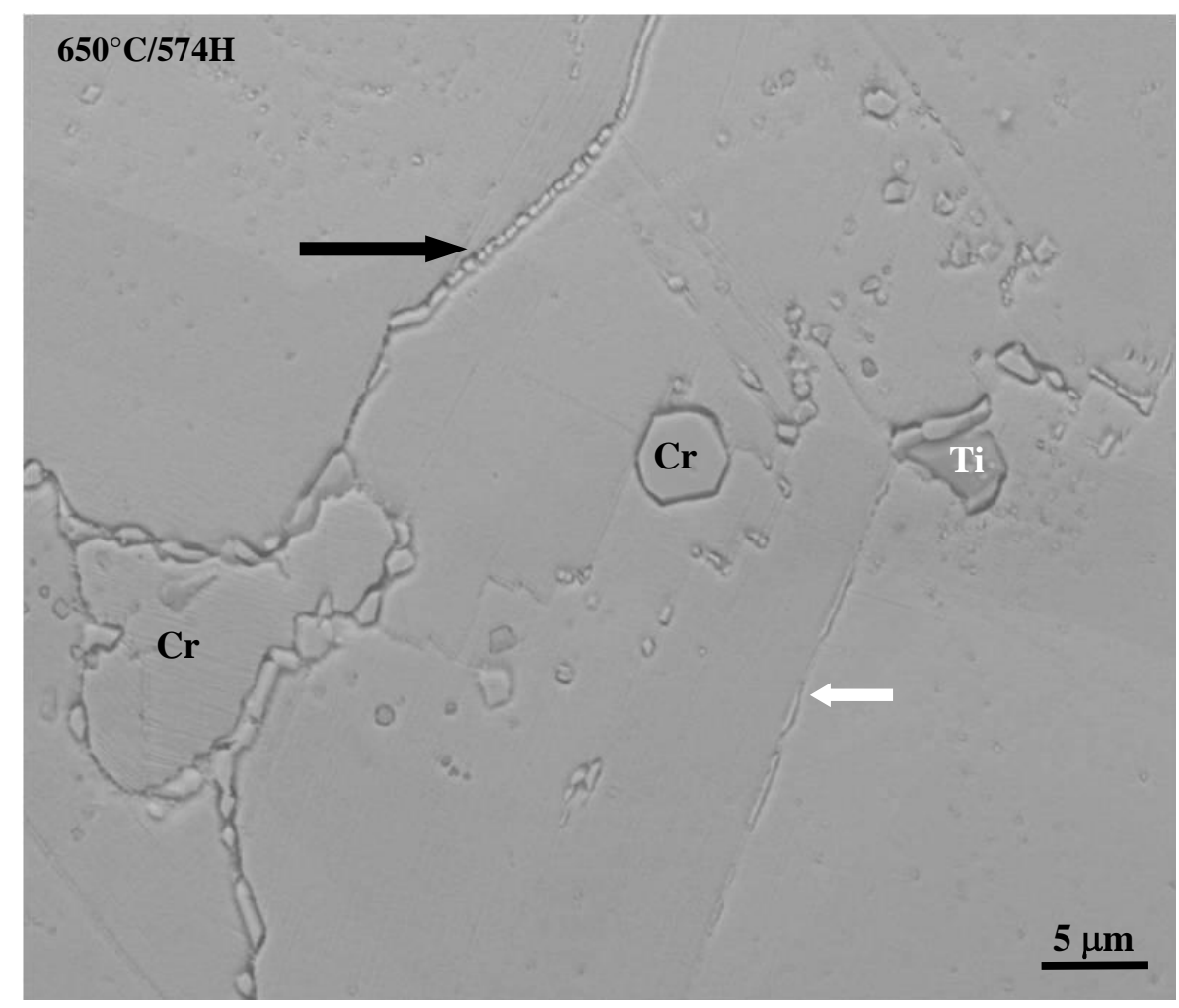

Figure 4 Scanning electron micrograph of creep-exposed sample. The blocky shape (darker contrast, marked ' $\mathrm{Ti}$ ') near the twin boundary (marked with a white arrow) is Ti-rich phase, $\mathrm{TiN}$; facetted particles (marked ' $\mathrm{Cr}$ ') are distributed intragranular, at triple junctions and also decorating the grain boundary (black arrow), and twin boundaries (white arrow) are $\mathrm{Cr}$-rich phase, $\mathrm{Cr}_{23} \mathrm{C}_{6}$.

Fig. 4 shows that precipitates were found both intra- and inter-granularly in the creepexposed specimen. The precipitate morphology varied from a symmetric to a totally asymmetric morphology. The size of $\mathrm{Cr}$-based precipitates ranged from $1 \mu \mathrm{m}$ to $17 \mu \mathrm{m}$ and the area fraction was $6.3 \%$. The size of Ti-based precipitates was $3 \mu \mathrm{m}$ to $5 \mu \mathrm{m}$ and the area fraction was $0.8 \%$. The area fraction of Cr-precipitates increased from $1.4 \%$ in the 'asreceived' to $6.3 \%$ in the creep-exposed.

The major precipitates found in as-received IN617 alloy and in the gauge length after creep exposure are shown in Table 2. 


\subsection{Fractography of creep-exposed sample}

The failure mechanism of the creep fractured specimen was analyzed using scanning electron microscopy and optical microscopy. A fractograph of the creep failed sample is shown in Fig. 5. The failure mechanism was intergranular fracture by decohesion of the grain boundaries. Intergranular creep fracture involves the nucleation, growth and subsequent linking of voids at grain boundaries to form two differing types of cavities, wedge type cavities and isolated type cavities. Wedge type cavities are associated with cracking at grain boundary triple points and form by grain boundary sliding. The formation of cavities is controlled by diffusion-controlled processes. Triple point wedge cracking (marked) and creep cavitation (arrowed) are shown in Fig. 5.

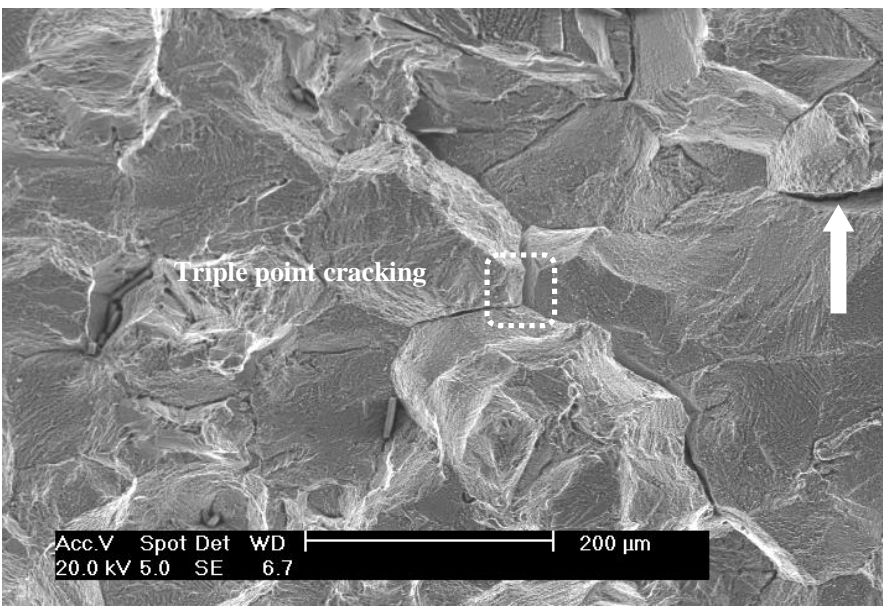

Figure 5 Intergranular creep failure of creep-exposed sample $\left(650^{\circ} \mathrm{C}\right.$ for 574 hours duration, intermediate stress).

The failure mechanism of the sample was further confirmed by optical and scanning electron microscopy of a polished cross-section of the fractured surface. Fig. 6 shows further confirmation of wedge cracking, decohesion and crack propagation along the grain boundaries in the creep-exposed sample $\left(650^{\circ} \mathrm{C}\right.$ for $574 \mathrm{Hrs}$ creep duration). The direction of loading is shown by the arrows in Fig. 6. The open cracks intruded inside the sample to a depth of 100 to $500 \mu \mathrm{m}$. 

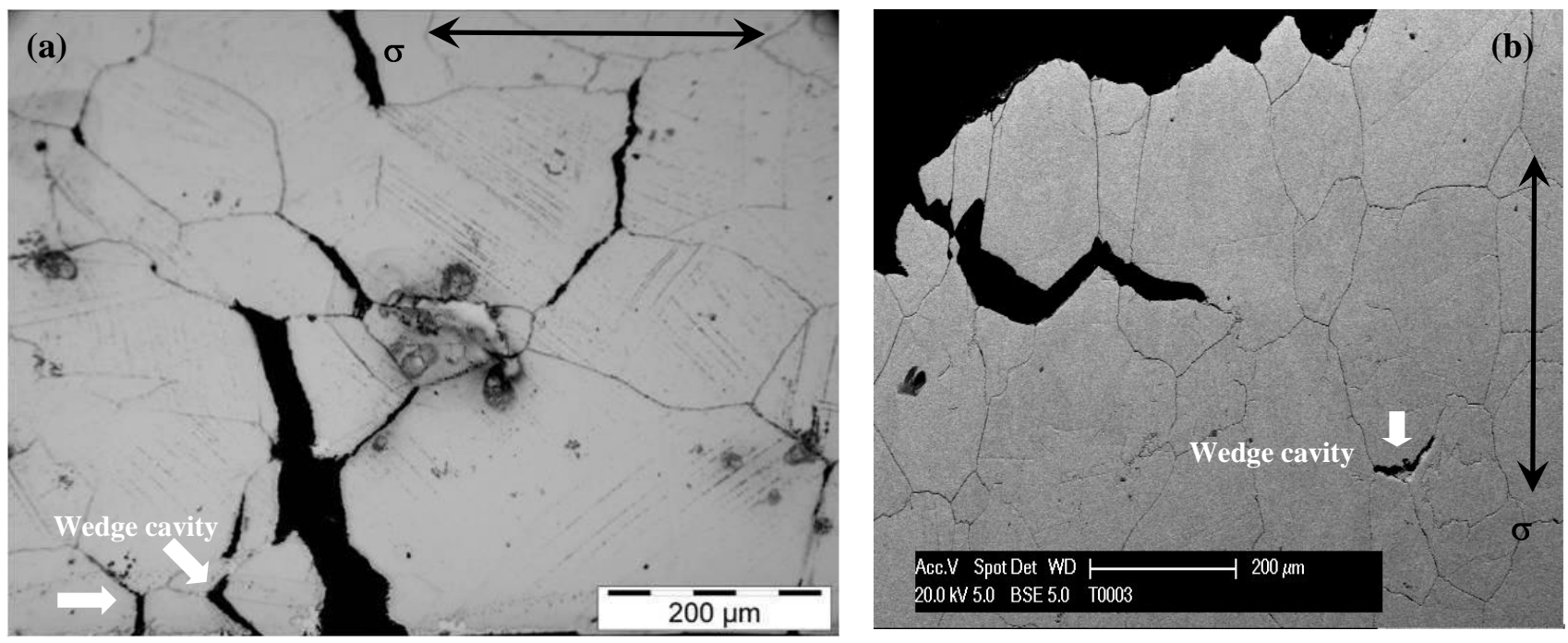

Figure 6 (a) Optical micrograph, $1 \mathrm{~cm}$ behind the fracture surface (b) SEM micrograph showing wedge cracking and grain boundary decohesion in creep-exposed IN617 alloy.

\subsection{Hardness profile for creep-exposed IN617}

Hardness was measured at $2 \mathrm{~mm}$ intervals along the head and gauge length of the longitudinally-sectioned specimen of the creep-exposed sample. The results of the hardness testing are shown in Fig. 8. Each hardness value is an average of three indentations across the diameter of the specimen. The error bars show the $90 \%$ confidence limits.

In Fig. 8, it can be seen that the hardness in the head region of the specimen, where it may be assumed that the major effect on the sample from creep exposures is from the thermal effects with minimal effect from stress, the hardness is considerably lower than the hardness measured along the gauge length. The head hardness has however increased substantially in the creep-exposed sample above that of the 'as-received' sample, which had a hardness of 186.6Hv. The average value of Vickers hardness in the gauge length was $334 \mathrm{Hv}$. This sample showed little reduction in area at failure (17.6\%). When the microstructure was analysed, the sample showed extensive precipitation of $\mathrm{Cr}-$, and $\mathrm{Ti}$-enriched precipitates had occurred throughout the matrix. The rise in hardness observed in the head and gauge of the specimen is attributed to further development of the precipitates (viz. the area fraction of $\mathrm{Cr}_{23} \mathrm{C}_{6}$ has increased from $1.4 \%$ in the as-received sample to $6.3 \%$ in the creep-exposed sample). 


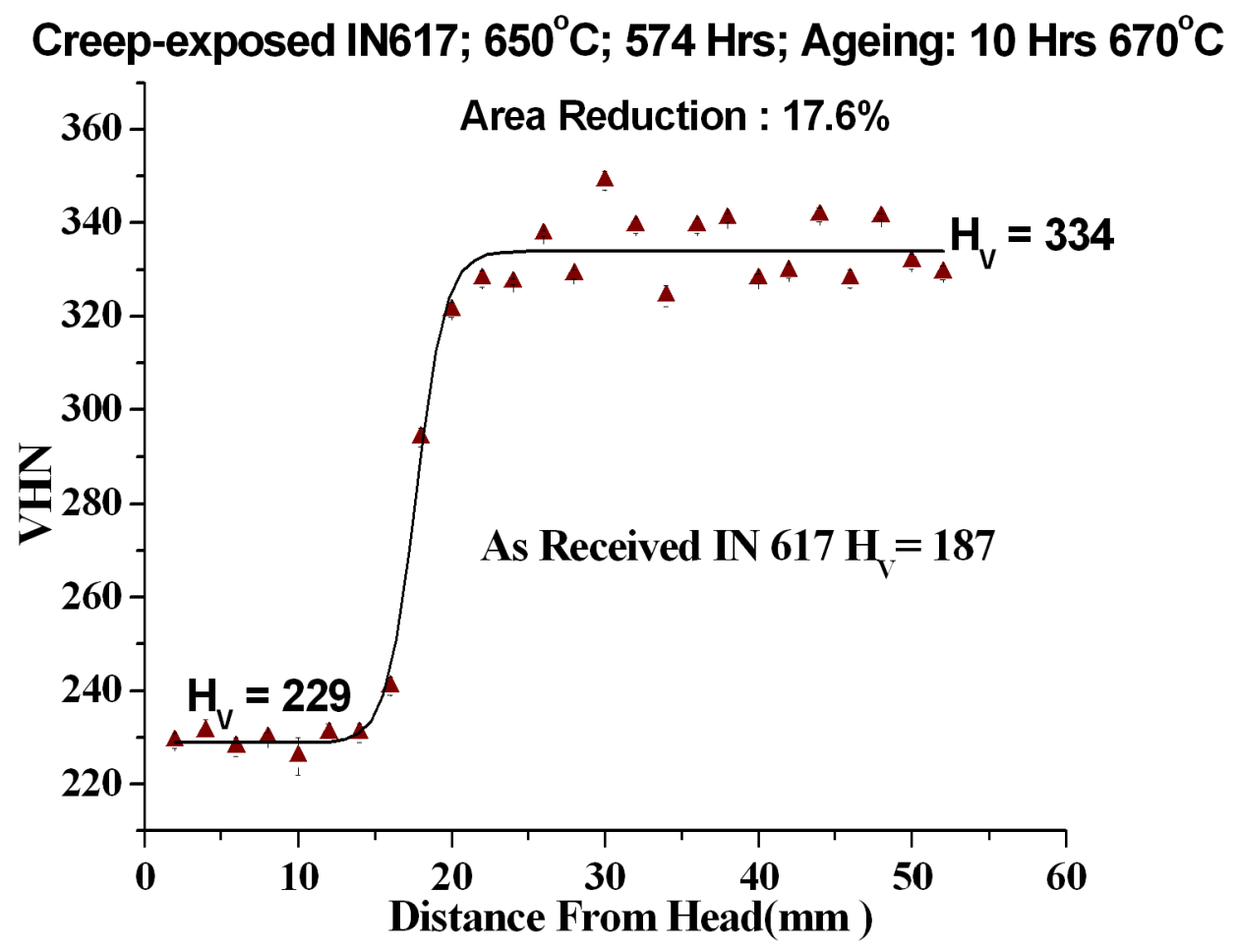

Figure 7 Hardness versus distance from head for the creep-exposed sample at $650^{\circ} \mathrm{C}$.

The internal damage has occurred from coarsening of the carbide phase, grain growth and grain boundary creep voidage. Internal damage of this nature does not lead to any dimensional changes in the specimen but results in a decrease of the high temperature mechanical properties such as creep-rupture strength $[22,23]$.

\subsection{Transmission electron microscopy}

The microstructure of creep exposed IN617 alloy has been analysed using analytical transmission electron microscopy. Phase identification was performed using electron diffraction patterns and X-ray spectrometry (EDS).

Fig. 8 shows a montage of TEM micrographs of the creep exposed sample. The incident direction of the electron beam is [001]. The SAED pattern indicates that the precipitates $\operatorname{are} \mathrm{Cr}_{23} \mathrm{C}_{6}$ phase. The dislocation activity near the carbide particles is arrowed. Grain boundaries are decorated with varying sizes of $\mathrm{Cr}_{23} \mathrm{C}_{6}$ carbide particles. Their large variation in size might indicate that they formed both at different stages of the thermal treatment and during creep exposure. 

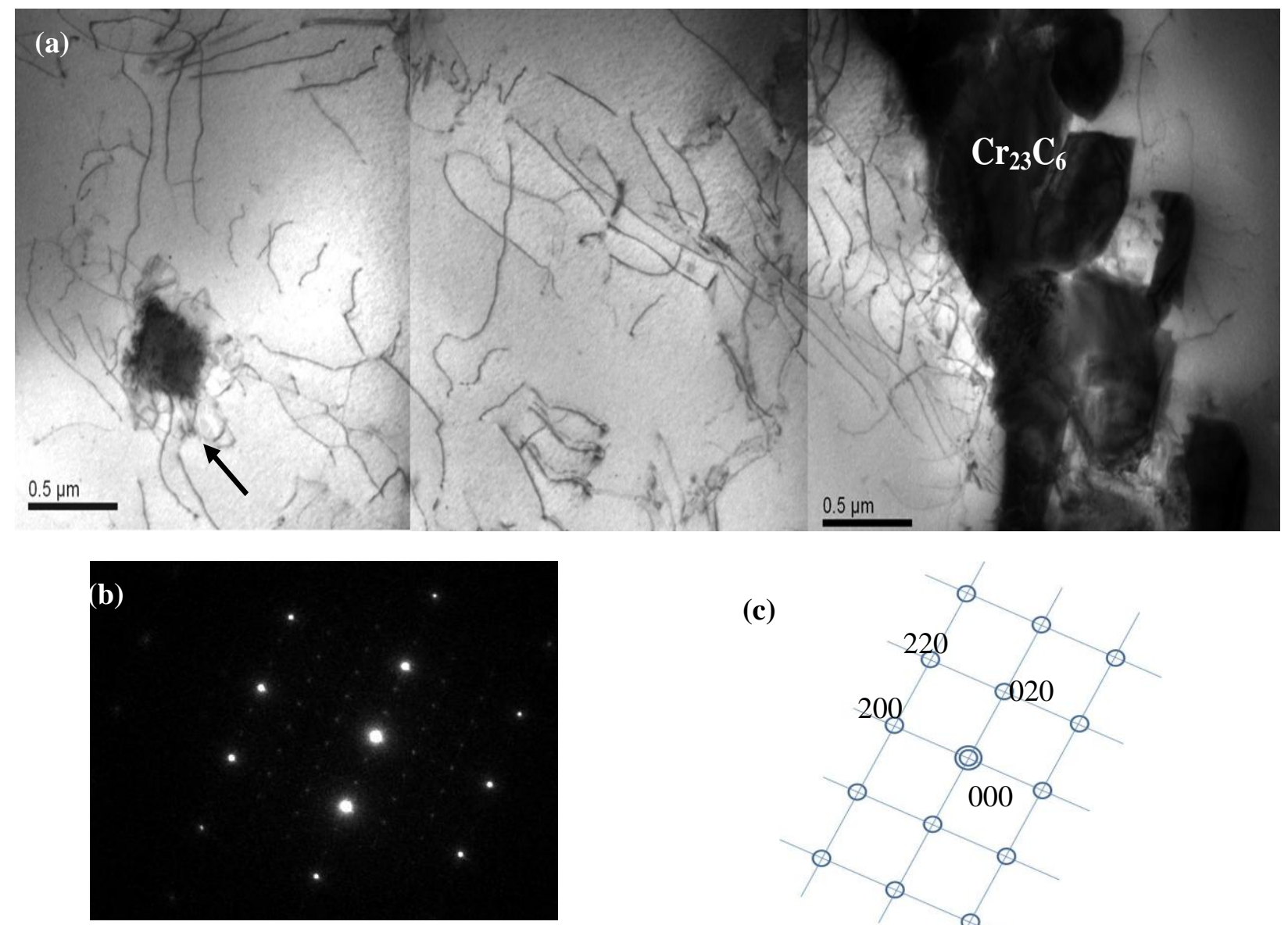

(c)

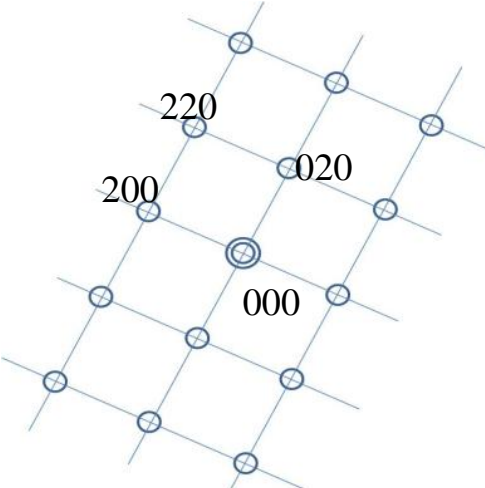

Figure 8 (a) Montage of bright field TEM micrographs of creep-exposed sample $\left(650^{\circ} \mathrm{C}\right.$; rupture life $\left.574 \mathrm{Hrs}\right)$ illustrating dislocation structure, precipitate particles and dislocation-particle interactions in austenitic $\gamma$ - matrix (arrowed). (b) Selectedarea electron diffraction pattern of $\mathrm{Cr}_{23} \mathrm{C}_{6}$ particle. (c) Key diagram. The direction of beam is along [001].

Fig. 9a depicts a region at relatively low magnification. Along the grain boundary fine scale precipitates have formed. A magnified image of the region (marked) is shown in Fig. 9b. These tiny precipitates $(<0.1 \mu \mathrm{m})$ are potentially second generation carbides formed in the material during the application of stress. These carbides were found on the grain boundaries and near the larger precipitates. 

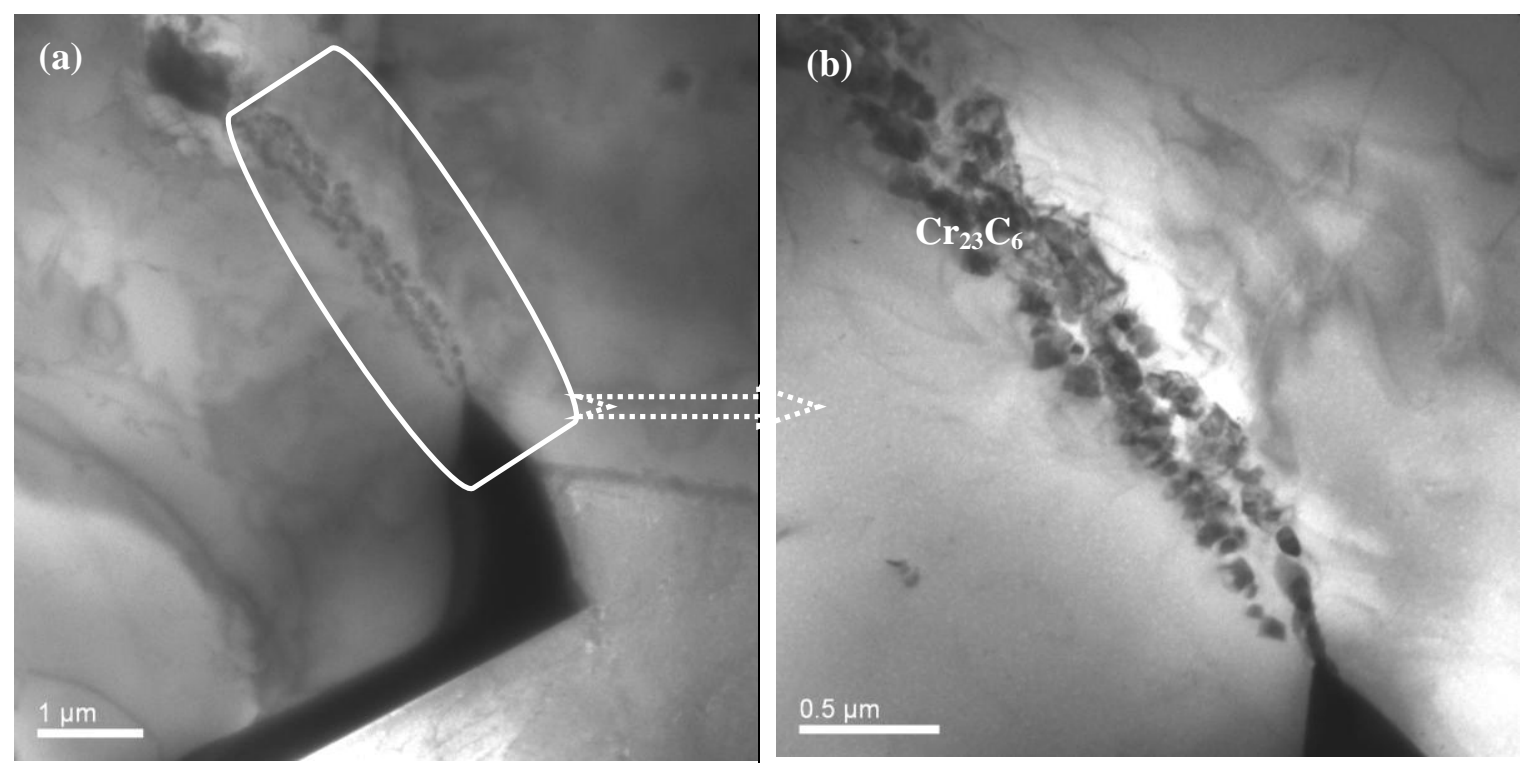

Figure 9 TEM micrographs illustrating the different scales of second phase carbides in creep-exposed sample. (a) Micrograph shows finer scale precipitates in between the particles. (b) Higher magnification of marked area of (a).

\subsection{X-ray diffraction}

$\mathrm{X}$-ray measurement was performed on the as-received and creep exposed samples to characterize the precipitates formed under the application of intermediate stress and high temperature. The resultant spectrum for the creep-exposed sample is shown in Fig. 10. 


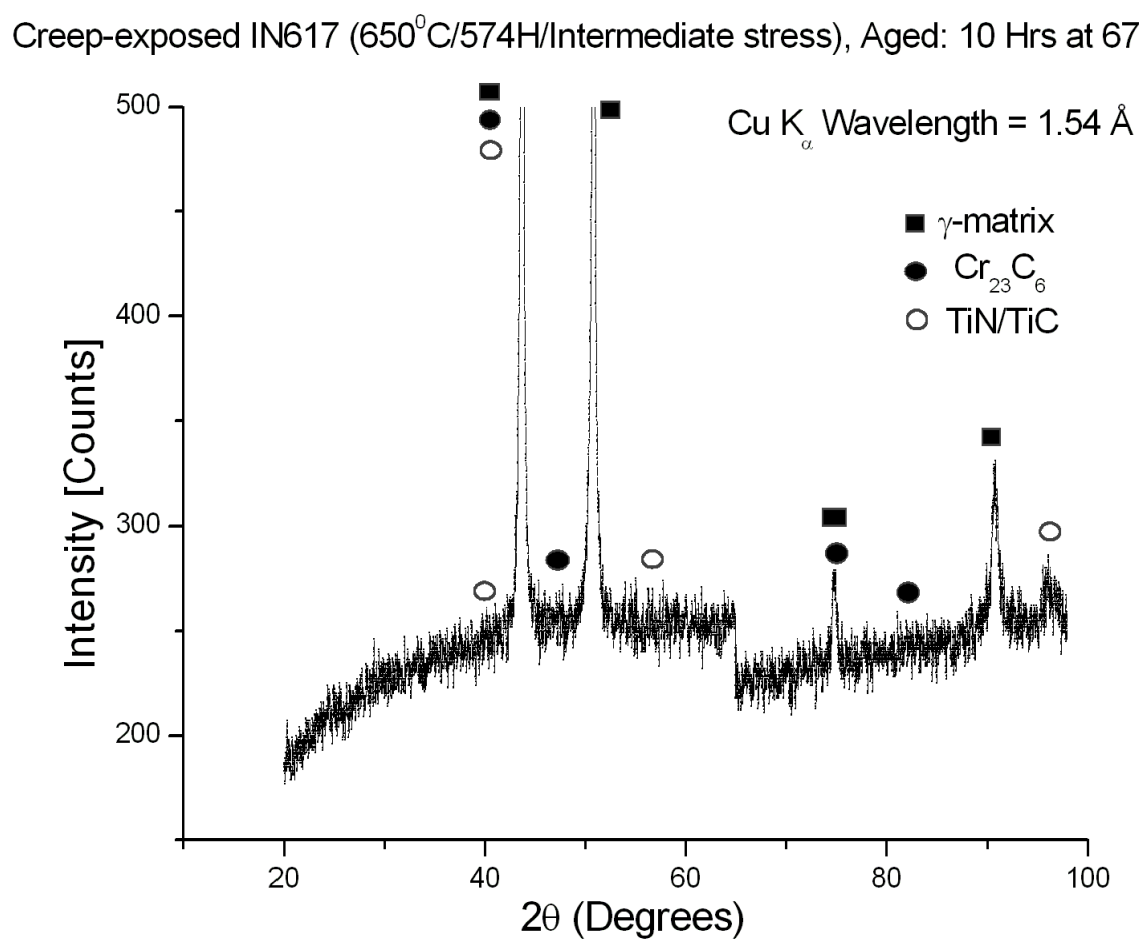

Figure 10 X-ray diffractograph (Intensity vs. 20) of creep-exposed sample.

One of the difficulties of identifying precipitates in IN617 is that the peak positions for a number of the carbides and nitrides overlap. Following the approach of Mukherji et al. [20] peak separation has been performed using PeakFit ${ }^{\circledR}$ software [19]. Thus, the precipitates in the sample were identified to be $\mathrm{Cr}_{23} \mathrm{C}_{6}$ and TiN/TiC by analysis of the XRD trace.

\section{Conclusions}

The experimental observations on phase precipitation and microstructural evolution in creepexposed IN617 $\left(650^{\circ} \mathrm{C}, 574\right.$ hours, intermediate stress) are summarized as follows:

i. The average grain size of the 'as received' IN617 was $120 \mu \mathrm{m}$, but for the creep exposed IN617 specimen the average grain size was increased to $158 \mu \mathrm{m}$.

ii. The rise in hardness observed in the creep-exposed sample is thought to be associated with additional $\mathrm{Cr}_{23} \mathrm{C}_{6}$ precipitation during creep exposure.

iii. Precipitates in as-received and in the creep-exposed sample were identified as Cr-enriched $\left(\mathrm{M}_{23} \mathrm{C}_{6}\right)$ and Ti-enriched (TiN). In the creep-exposed sample, the precipitates were found to precipitate in large proportions at twin and grain boundaries, but otherwise, precipitates were randomly distributed throughout the matrix. 
iv. Precipitates were found to have varying morphology from a symmetric to an unsymmetric morphology.

v. The creep fracture mode was found to be predominantly intergranular in nature.

\section{Acknowledgements}

The authors would like to thank ALSTOM Power Ltd. for supplying creep exposed samples and wish to acknowledge the UK Government's Technology Strategy Board for providing financial support to carry out this work. Mr G. Clark is thanked for help with microscopy and specimen preparation and $\mathrm{Mr} \mathrm{T}$ Forryan is thanked for preparing samples for XRD analysis.

\section{References}

1) R. Viswanathan, J.F. Hanry, J. Tanzosh, G. Stanko and J. Schlingledecker: Proceedings of the Conference on 'Creep and Fracture at High Temperature Components' (Eds. I.A. Shibli, S.R. Holdsworth and G. Merckling), 12-14 Sept. 2005, DEStech Publications, Lancaster, PA, 59-74.

2) R. Viswanathan, J. F. Henry, J. Tanzosh, G. Stanko, J. Shingledecker, B. Vitalis and R. Purgert: Journal of Materials Engineering and Performance, 2005, 14(3), 281-292.

3) S. Zhao, X. Xie, G. D. Smith and S. J. Patel: Materials Science and Engineering: A, 2003; 355, 96-105.

4) F. Tancret and H.K.D.H. Bhadeshia: Proceedings of the 6th International Charles Parsons Turbine Conference, on 'Engineering Issues in Turbine Machinery, Power Plant and Renewables' (Eds. A. Strang, R. D. Conroy, W. M. Banks, M. Blackler, J. Leggett, G. M. McColvin, S. Simplson, M. Smith, F. Starr and R. W. Vanstone), Trinity College Dublin, Ireland, 16-18 September 2003, Institute of Materials, London 2003; 525-535.

5) Q. Wu, H. Song, R.W. Swindeman, J.P. Shingledecker and V.K. Vasudevan: Metallurgical and Materials Transactions A, 2008, 39, 2569-2585.

6) R.C. Reed: Proceedings of the Seventh International Charles Parsons Turbine Conference on 'Power Generation in an Era of Climate Change', (Eds. A Strang, W.M. Banks, G.M. McColvin, J.E. Oakey, R.W. Vanstone), University of Strathclyde, Glasgow, 11-13th September 2007, Institute of Materials, London 2007; 89-97. 
7) G.W. Meetham: High Temperature Alloys for Gas Turbines and Other Applications, (Eds. W. Betz, R. Brunetaud, D. Coutsouradis, H. Fischmeister, T.B. Gibbons, I. Kvernes, Y. Lindblom, J.B. Marriott, D.B. Meadowcroft), D. Reidel Publishing Company, Dordrecht, Holland, 1986, 1-18.

8) F. Meyer-Olbersleben, N. Kasik, B. Ilschner and F. Rézaï-Aria: Metallurgical and Materials Transactions A, 1999, 30(4), 981-989.

9) C. Barbosa, J.L. Nascimento, I.M.V. Caminha and I.C. Abud: Engineering Failure Analysis, 2005, 12(3), 348-361.

10) W. Ren and R. Swindeman: Journal of Pressure Vessel Technology, 2009, 131 (2), 024002(1)-024002(15).

11) J.C. Hosier and D.J. Tillack: Metals Engineering Quarterly, 1972, 12 (3), 51-55.

12) W.L. Mankins, J.C. Hosier and T.H. Bassford: Metallurgical and Materials Transactions B, 1974, 5 (12), 2579-2590.

13) O.F. Kimball, G.Y. Lai and G.H. Reynolds: Metallurgical Transactions A, 1976, 7 (12), 1951-1952.

14) S. Kihara, J.B. Newkirk, A. Ohtomo, and Y. Saiga: Metallurgical Transactions A, 1980, 11(6), 1019-1031.

15) P. Ganesan, G.D. Smith and D.H. Yates: Materials and Manufacturing Processes, 1995, 10 (5), 925-938.

16) P.J. Ennis, W.J. Quadakkers, and H. Schuster: Materials Science and Technology, 1992, 8, 78-82.

17) J.R. Davis, Davis \& Associates (Eds.): Heat Resistant Materials, ASM Specialty Handbook, 331, 1999, ASM International, Materials Park, OH.

18) ASTM Standard E112-95, 03.01(1996): Standard test methods for determining average grain size, ASTM International, West Conshohocken, PA, 1996.

19) PeakFit ${ }^{8}$ 4.12, SeaSolve Software Inc. 1999-2003.

20) D. Mukherji, R. Gilles, B. Barbier, D. Del. Gemovese, B. Hasse, P. Strunz, T. Wroblewski, H. Fuess, J. Rösler: Scripta Materialia, 2003, 48, 333-339.

21) R. Krishna, S. V. Hainsworth, S.P.A. Gill, A. Strang and H. V. Atkinson: Proc. $2^{\text {nd }}$ Int. ECCC Conf. on 'Creep \& fracture in high temperature components - Design \& Life assessment' (Eds. I.A. Shibli and S.R. Holdsworth), 21-23 April 2009, Zurich, 764-776.

22) Z. Mazur, A.L. Ramìrez, J.A.J. Islas and A.C. Amezcua: Engineering Failure Analysis, 2005, 12, 474-486. 
23) A.M. Wusatowska-Sarnek, M.J. Blackburn, and M. Aindow: Materials Science and Engineering A, 2003, 360 (1-2), 390-395. 